\author{
Andrej Bjelaković \\ University of Belgrade \\ Faculty of Philology \\ Belgrade, Serbia \\ Biljana Čubrovic \\ University of Belgrade \\ Faculty of Philology \\ Belgrade, Serbia
}

\title{
ATTITUDES REGARDING THE REALISATION OF THE LOT VOWEL IN ADVANCED SERBIAN EFL SPEAKERS ${ }^{* * *}$
}

\begin{abstract}
In this paper we present the results of a survey, a forced choice questionnaire, which focused on the pronunciation of the LOT vowel among first-year students of English Language and Literature, whose L1 is Serbian $(n=102)$. This was part of a series of surveys designed to determine pronunciation preferences of Serbian English learners and the extent of the gradual drift towards American pronunciation that has been noticed in recent decades. The informants were divided into two subgroups according to their answer to the first question, which determined whether the participant was oriented towards GA (General American) or towards SBS (Southern British Standard). Different survey questions tested the pronunciation of the Lот vowel in different contexts with different factors taken

E-mail address: b.andrej@fil.bg.ac.rs

** E-mail address: biljana.cubrovic@fil.bg.ac.rs

*** This paper was presented at the Fifth Belgrade International Meeting of English Phoneticians (BIMEP 2020), 20-21 March 2020, Faculty of Philology, University of Belgrade.
\end{abstract}


into account: number of syllables, frequency of the selected LoT words, spelling, and the presence of the given word as a loanword in Serbian.

The results show that the much smaller subgroup that preferred SBS was much more accurate in their vowel choices, only occasionally opting for the GAappropriate vowel in place of the SBS LOT vowel (85\% accurate), as opposed to the larger GA subgroup which displayed a lot of vacillation and uncertainty (29\% accurate). The hypothesis that high frequency words will have a higher chance of being assigned the appropriate vowel was confirmed. However, other factors did not seem to have a noticeable effect. On the whole, the results support a previous observation that many advanced learners in fact speak an amalgam of British and American reference accents.

Key words: LOT vowel, Serbian EFL speakers, GA, SBS, accent attitude

\section{Introduction}

\subsection{Background}

For years, the authors of this paper have noticed a large-scale, gradual drift towards American pronunciation in the speech of English Language and Literature students at the University of Belgrade, despite the fact that the Southern British Standard model of pronunciation is the only one explicitly taught in detail in English Phonetics and Pronunciation classes. This state of affairs has prompted previous inquiries (Čubrović and Bjelaković 2020a; Čubrović and Bjelaković 2020b), which in turn suggested the realization of the Lот vowel as an avenue for further research. Among other things, these studies indicate that there is a degree of confusion among Serbian L2 speakers regarding the vowel in this lexical set (in addition, Bjelaković (2015) suggests there is often a discrepancy between the variety informants say they use and the actual sound they employ in this lexical set). Therefore, we devised the present study in order to have a closer look upon learners' attitudes regarding the LOT vowel. The results of this and other similar studies could be potentially helpful in pointing to the main sources of confusion when it comes to advanced Serbian learners' pronunciation of English, and could consequently lead to reassessing the 
Andrej Bjelaković, Biljana Čubrović: Attitudes Regarding the Realisation...

emphasis and approach to teaching English pronunciation in the English Department ${ }^{1}$.

We will look into several factors that may influence the students' choice of pronouncing the цот vowel: frequency of the word in question, number of syllables, and whether they exist as common anglicisms in Serbian. The initial hypothesis is that higher frequency of use may trigger the students who opted for American pronunciation to stay true to the chosen pronunciation model. Discussed will also be the influence of the number of syllables (1,2 or more) and the influence of spelling of the English loanwords in Serbian (e.g. popular, Washington).

\subsection{AmE vs. BrE pronunciation attitudes and learner behaviour}

At various points in the 1990s, different authors anticipated the imminent change of guard, as it were, with American pronunciation starting to dominate the EFL scene. Thus, Bradac and Giles (1991) suggested that Swedish students of English as a Foreign Language may evaluate a Standard American accent (SA) more favourably than an RP accent on certain dimensions, and consequently be more motivated to learn SA (quoted in Ladegaard 1998). Furthermore, Graddol et al. (1999: 8) claimed that:

... an older person may strive for a flawless RP accent, but a younger person is influenced by American [...] Where once upon a time there might have been a British colonial veneer, there will be an American veneer. This will happen to native and foreign users of English. And demographically in the future it will be a veneer over millions and millions of people.

Similarly, Bayard et al. (2001: 44) concluded that:

American imagery is now employed willy-nilly by the entire world [...] American English seems to be winning hands down, and [...] American English, not British English, will remain the major global form of English into the indefinite future.

1 Some English departments, such as the one in Nijmegen, have long since offered courses in both British and American pronunciation (Gussenhoven 1992: 472). Rindal reports that at the University of Oslo six of the seven groups are taught the phonetics of RP while one group is taught General American (Rindal 2010: 241). 
Seeking to check if these predictions were true, Ladegaard analysed the attitude-behaviour relations of Danish high school students regarding the pronunciation of English (Ladegaard 1998). He found that, while the teenagers' attitudes largely matched their stated attitudes, their cultural preferences went in a different direction. Namely, in terms of accents, "RP appears to be the unsurpassed prestige variety in this Danish context; it is rated most favourably on all status and competence-dimensions, and it is seen as the most efficient, beautiful and correct accent of English" (Ladegaard 1998), and likewise the "result of the reading-test showed that $91 \%$ of the subjects had a predominantly British pronunciation." On the other hand, participants seemed to prefer American to British culture (participants opted for American culture (39.6\%); other (both British and American; Australian; Irish or Canadian) (39.6\%); British culture (18.7\%)).

Ladegaard also points out that American TV programmes far outstripped British ones on Danish television at the time, which is undoubtedly related to the impact and dissemination of American culture in Denmark (during a randomly picked week " $57 \%$ of [the] programmes were Danish productions, 34\% were American, 5\% were British and the remaining $4 \%$ were productions from other countries") $)^{2}$.

Several years later, Ladegaard and Sachdev (2006) conducted a similar study. Again, a survey of TV programmes was included, with American programmes comprising an even higher percentage (43\% this time). And again, there was a language/culture discrepancy, with the majority of participants preferring a British accent and also speaking with a British accent, but opting for American culture over British culture.

Norwegian high school students $(n=23)$, on the other hand, pronounced more than two thirds of the analysed tokens with an Americanlike pronunciation, as Rindal (2010) reports. All four phonological variables under scrutiny were pronounced with a majority of AmE variants (the four variables were rhoticity, t-voicing, the GOAT vowel and the LOT vowel; overall, students produced the American variant $67 \%$ of the time). This is despite the fact that little over half of the participants said they aimed for a British accent. In other words, unlike in Ladegaard's studies here we see a discrepancy between the self-reported variety and actual pronunciation features. In the listening test RP speakers received the most

2 In a similar vein, Bjelaković (2015) had a look at English-speaking programmes broadcast in Serbia in 2015, and reported that 80\% were North American, 16.5\% were British or Australian, and the remaining 3.5\% were mixed. 
Andrej Bjelaković, Biljana Čubrović: Attitudes Regarding the Realisation...

favourable evaluation for 11 dimensions, while the remaining 6 dimensions were GenAm-favoured. Rindal concludes that while British English still has higher status than American English, and is the preferred model of pronunciation, American cultural hegemony does have an impact on the L2 situation in Norway. A few years later, Rindal conducted much the same study, with very similar results in terms of the phonological features being predominantly American (this time, however, 29 participants said they aimed at an American accent, and 23 said the same for the British accent) (Rindal 2013). Rindal's figures can be compared with those of Van der Haagen a decade earlier who conducted a comparable study with Dutch students of English (Van der Haagen 1998, quoted in Rindal 2010). There the participants used American pronunciation only 39.1\% of the time.

In terms of research done in Serbia, Paunović's survey of English Language and Literature students at the University of Niš (Paunović 2009) showed the discrepancy between the most prestigious and the selfreportedly most used pronunciation standard. Asked "What kind of accent would you like to have?", half of the participants opted for the "British" accent (50\%). Conversely, when asked to describe their own accent, most participants answered "American" (45.6\%) (the remaining answers were "neutral" (24.6\%), "Serbian English" (14.9\%), and "British" (14.9\%)).

Čubrović and Bjelaković (2020a) report that their respondents, who are first-year students of English Language and Literature at the University of Belgrade, predominantly opt for General American (GA) when asked about which reference accent they use or hear more often.

Based on the overview of previous studies, it would appear that the use of American English pronunciation features is increasing among EFL learners in a number of countries. The participants in the cited studies mostly grew up with traditional media, primarily television and cinema, through which they were, when it comes to English, exposed primarily to authentic American speech. As Kautzsch (2017: 38) duly points out there are many influencing factors that feed into the creation of a learner's interlanguage (IL):

[...] heterogeneity in learner language might not be as orderly or structured all the time. A context in which learners are faced with highly heterogeneous input, resulting from two native standards, from the English of non-native teachers, and from a variety of regional accents of L1, suggest the presence of many competing rules in the learners' ILs. 
Finally, we expect that findings of the present study will speak to the degree to which the pronunciation of advanced Serbian learners of English corresponds to what is sometimes termed Amalgam English. Cruttenden describes this as "an amalgam of native speaker Englishes, together with some local features arising from a local L1" (2014: 327). We hope to gain further insight into how consistent our participants are in using their chosen variety of English.

\subsection{The LOT vowel}

A well-known, salient difference between SBS (Southern British Standard) and GA (General American) involves the quality of the vowel in the standard lexical set LOT $^{3}$ (Wells 1982). On the one hand, in SBS, there is a short, rounded vowel, currently approaching [0] in quality, although phonemically, it is traditionally transcribed as /p/ (Cruttenden 2014: 126). On the other hand, GA features a longer, usually fully unrounded, open vowel, of the [a:] type. In addition, this lexical set is merged with the PALM set for almost all speakers of North American English (i.e. bother rhymes with father) (this appears to have taken place by mid-19 ${ }^{\text {th }}$ century; see Krapp 1925: 141-148; Wells 1982: 122, 245-246; Labov et al. 2006: $12-$ 13). Finally, there is also a difference in the distribution of words, since some words that historically belonged to LOт have moved to тноUGHT in GA, specifically "before back nasals, as in strong, song, long, wrong, etc.; before voiceless fricatives (in loss, cloth, off, etc.), and irregularly before /g/, as in $\log , h o g, d o g, f o g$, etc. This process occurred by lexical diffusion, leaving many less common words in the [Lот] class, such as King Kong" (Labov et al. 2006: 13). Of course, this difference in distribution is increasingly a moot point, considering the advance of the LOT-тноUGHT merger across North America (Labov et al. 2006; Grama and Kennedy 2019).

Returning to the difference in quality between the usual SBS and GA realisation, not only is it quite noticeable, but it arguably makes the GA realisation of the sound cross a perceptual threshold for Serbian speakers, to whom the GA variant sounds closer to their /a/ used with a long pitch accent (usually in the [ä:] [p⿱亠䒑:] range), as opposed to the SBS realization,

3 Historical sources of this vowel are primarily the Old English /o/ (e.g. docga 'dog'), and the Middle English /a/ after /w/ (e.g. wasp, wash, watch, etc.), as well as a smaller number of words that had the Old English /a/ before clusters /ng/ and /nd/ (e.g. strong, long, bond, etc.) (Dobson 1957: 528, 565, 717). 
Andrej Bjelaković, Biljana Čubrović: Attitudes Regarding the Realisation...

which sounds a lot like the Serbian /o/ used with a short pitch accent (around [0], see Bjelaković 2018).

In terms of contemporary EFL/ESL learners in other countries, this lexical set appears to pose problems for a variety of experienced non-native speakers. Thus, for example, Kautzch reports that even his American English target accent group of German speaking students of English did not merge LOT and PALM (Kautzch 2012: 234-235). In another study, Kautzsch (2017: 234,240 ) found that the Lот set shows a great deal of variability that is a result of a merger of Lот and тноиGнт, even more so in the American English target accent groups that spent less time in the US. Kalaldeh, similarly, claims that many if not most Arab speakers adopt a GA accent, and yet the "realization of the LOT vowel is a common error and is usually rendered as the RP rounded [p]" (Kalaldeh 2016: 403). And according to Hommel (2017), Dutch students' LOT vowel is often mistaken for STRUT by British listeners (despite the fact that Dutch has a short, rounded / $/ \mathrm{s}$, as in the Dutch 'bot'). This may well be because younger learners of English are influenced by the GA цот, and remove the lip-rounding (causing British listeners to hear STRUT).

\section{Methodology}

This study gathered self-reported data regarding the usage of the LOT vowel (among other things). As such, it possesses obvious shortcomings, since the speakers are not necessarily aware of their actual usage, and the answers they provide need not match their everyday production. To what degree the self-reported data match the learners' usage is, however, beyond the scope of this study.

A written questionnaire was distributed among the first-year English Language and Literature students at the Faculty of Philology, University of Belgrade. The number of respondents was 102. The questionnaire contained 23 questions, and they were grouped as follows:

- Questions 1-3 had to do with the varieties of English students use more, hear more or prefer listening to;

- Questions 4-6 were diagnostic questions looking into some of the most conspicuous phonetic differences between SBS and GA other than the Lот vowel, such as rhoticity vs. non-rhoticity, t-voicing and the TRAP-BATH split; 
- Questions 7-19 investigated various words of the Lot lexical set (differing in frequency, number of syllables, and whether or not they exist as common anglicisms in Serbian);

- Questions 20-23 involved further attitudes (easier vs. sounds better), the reason behind using the preferred variety, as well as the hypothetical choice of variety to be studied, if offered.

The informants were divided into two subgroups according to their answer to the first question, and the results will be reported contrasting the two subgroups, i.e. students oriented towards GA (General American) as opposed to those oriented towards SBS (Southern British Standard).

\section{Results}

\subsection{Questions 1-3}

Question 1 was "Which of these varieties of English do you use more often?", with only two options offered: SBS (Southern British English) and GA (General American) ${ }^{4}$. A majority of $77.5 \%$ students said they used GA more often. This means that of the total of 102 participants, 79 form our "GA group", while the remaining 23 form our "SBS group".

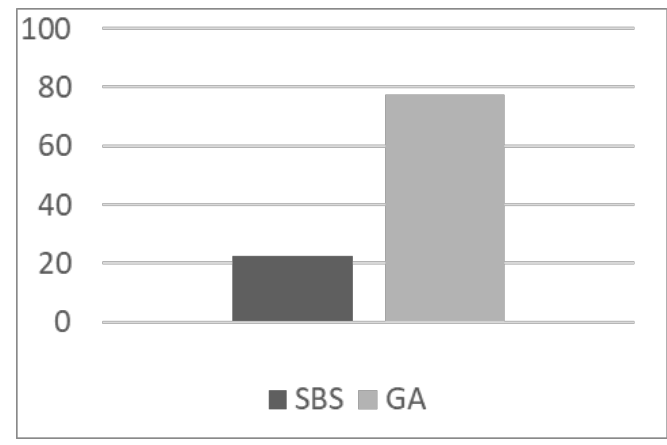

Graph 1: Preferred accent of participants

4 The participants were familiar with these labels, as well as with basic phonetic terms, having already had one semester of mandatory first-year courses in English Phonetics and Pronunciation. The main differences between the two reference accents had been briefly covered in the English Phonetics course, but the focus as ever was on SBS. 
Andrej Bjelaković, Biljana Čubrović: Attitudes Regarding the Realisation...

Question 2 was "Which of these varieties of English do you hear more often?", with the two options being the same as in the previous question. The two subgroups largely agree inasmuch as they are both overwhelmingly exposed to GA (95.5\% of the SBS group and 91\% of the GA group).

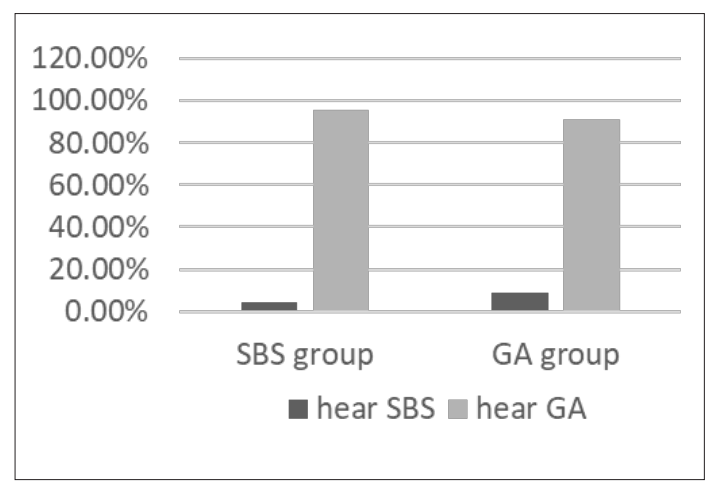

Graph 2: Variety participants report being more exposed to

Question 3 was "Which of these varieties do you prefer listening to?", eliciting the participants' attitude regarding which of the standard varieties is more "pleasing to the ear" or appealing. Here we see a stark difference between the two subgroups. Namely, while the SBS group overwhelmingly prefers listening to SBS (91.5\%), the GA group is split almost in half $45.5 \%$ say they prefer listening to SBS, whereas $55.5 \%$ say they prefer listening to GA.

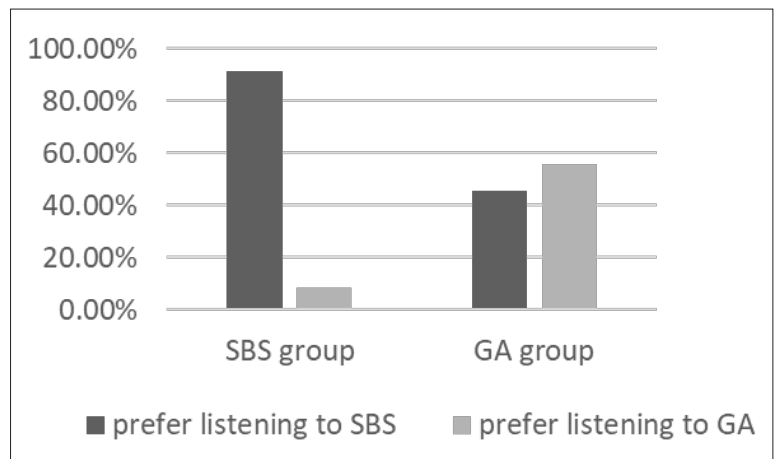

Graph 3: Preferred standard variety of English in terms of being listened to 


\subsection{Questions 4-6}

The next section of the questionnaire explored the level of consistency the two groups of students demonstrate. The questions asked involved some of the most common differences in pronunciation between GA and SBS: rhoticity, t-voicing, and the TRAP-BATH split.

Question 4 dealt with rhoticity, and it was framed as "Do you pronounce all your ' $r$ ' sounds in English?", with only two options being offered, "Yes" and "No".

Question 5 investigated the respondents' attitude towards t-voicing and it was framed as "Which sound do you use in the middle of words such as city, beautiful, letter?"; the possible answers were "a) t-like sound" and "b) d-like sound".

Question 6 dealt with the TRAP-BATH split and was framed as "Which sound do you use in words such as ask, path, answer?". The possible answers were "a) an e-like sound" and "b) an a-like sound".

Looking at the responses to the individual questions, we see that the SBS group reported t-voicing in $4.35 \%$ of the cases, pronouncing all $/ \mathrm{r} /$ sounds in $13 \%$ of the cases and using the same vowel in TRAP and BATH in $13 \%$ of the cases as well.

On the other hand, the GA group reported not being fully rhotic in $35.5 \%$ of the cases, not using t-voicing in 56\% of the cases, and using different vowels in TRAP and BATH in $33 \%$ of the cases.

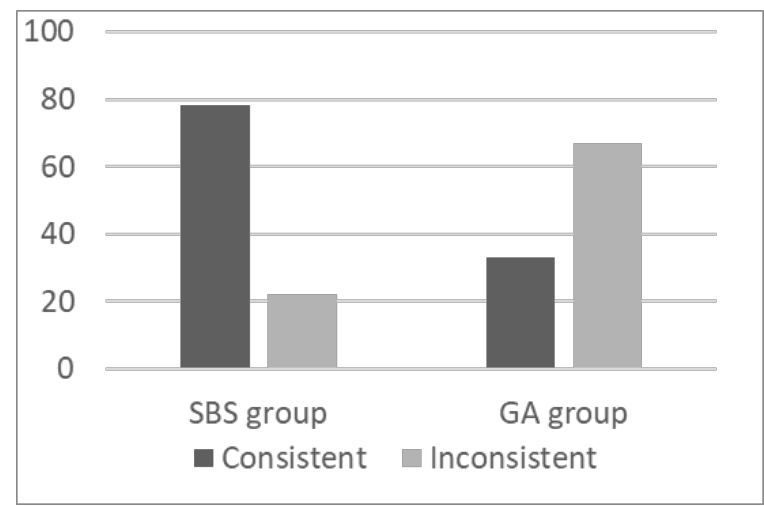

Graph 4: Levels of consistency based on the main salient differences between GA and SBS 
Andrej Bjelaković, Biljana Čubrović: Attitudes Regarding the Realisation...

To sum up, the SBS group showed a higher score in keeping in line with the expectations of their chosen pronunciation model, whereas the GA group's English is more of an amalgam of the British and the American reference accents.

\subsection{Questions 7-19}

All questions in the next section (7-19) involved a forced choice between an "o-like sound" and an "a-like sound"; the former was meant to represent the closer, rounded SBS-appropriate vowel, and the latter was meant to represent the open, unrounded GA-appropriate option (the labels also refer to Serbian vowels closest to the SBS /p/ and GA /a:/ respectively). Questions 8 and 10, however, had a third option as well, namely "vowels are different in these words". All the words were grouped together according to the following criteria: frequency, number of syllables, and whether they exist as common anglicisms in Serbian (in which case they will have /o/ in Serbian, except Washington, which is rendered as Vašington, with /a/). So, for example, words in questions 7 and 8 (see Table 1) were deemed frequent monosyllabic LOT words, whereas words in question 9 were monosyllabic words singled out as being not as commonly heard in everyday, spoken English (or rather two of them were, with watch displaying the less common spelling of Lот); questions 10 and 11 included disyllabic цот words, while questions 12 and 13 included trisyllabic Lот words; finally, words in questions 14-18 exist as loanwords in Serbian.

$\begin{array}{llll}7 & \text { God, body, job } & 14 & \text { golf } \\ 8 & \text { cop, shot, knock } & 15 & \text { hotdog } \\ 9 & \text { ox, pomp, watch } & 16 & \text { non-stop } \\ 10 & \text { bother, problem, common } & 17 & \text { modern } \\ 11 & \text { doctor, monster, promise } & 18 & \text { cosmos } \\ 12 & \text { possible } & 19 & \text { Washington } \\ 13 & \text { popular } & & \end{array}$

Table 1: Words used in questions 7-19 
Graph 5 shows the SBS group's responses to questions 7-19, arranged in descending order (with the highest proportion of SBS-appropriate, o-like, answers to the left). What we see is a high proportion of "correct", i.e. SBSappropriate answers. This seems to be especially true of high-frequency words, such as God, body, job, possible etc. However, the two questions that included the option "vowels are different in these words" show that more than a quarter of the SBS group opted for this extra response $(26 \%$ and $30 \%$, respectively).

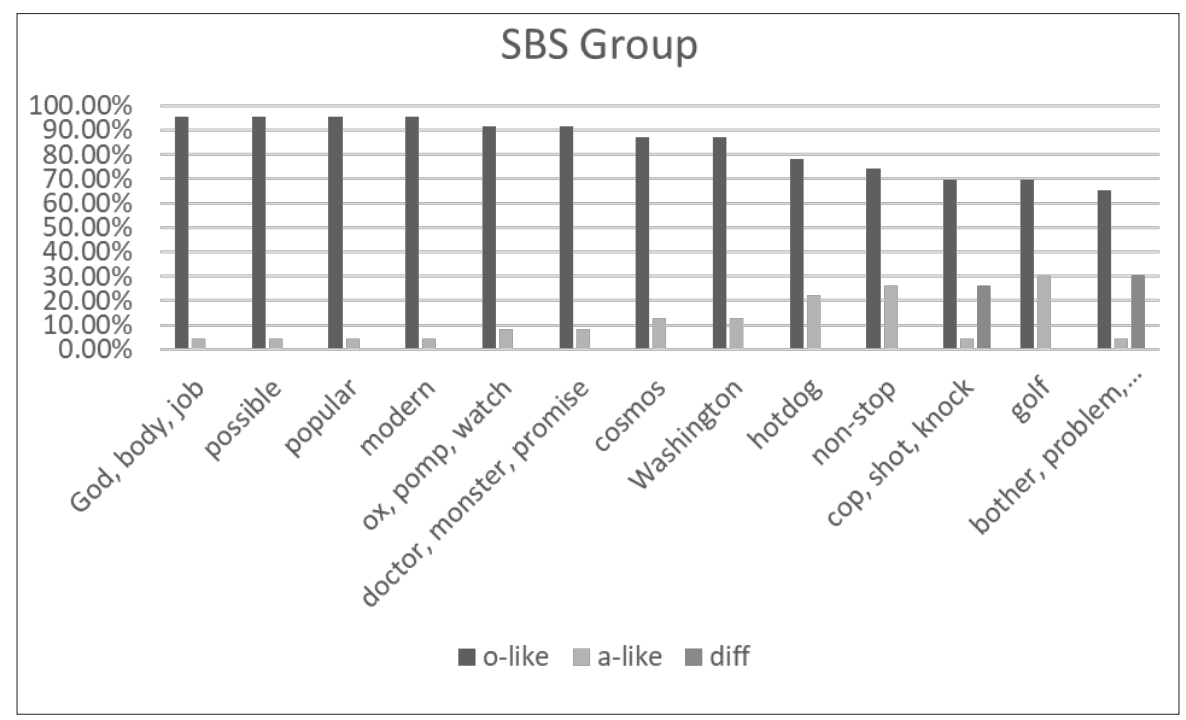

Graph 5: SBS group's responses to questions 7-19

Graph 6 shows the GA group's responses to questions 7-19, arranged in descending order (with the highest proportion of GA-appropriate, a-like, answers to the left). Here we see a situation drastically different from the one in Graph 5. The highest proportion of GA-appropriate answers was again present in the category of high-frequency words God, body and job, but even then, it barely exceeded 60\%. The majority of the Lот questions, on the other hand, showed a proportion of GA-appropriate answers that did not exceed $20 \%-25 \%$. As was the case with the SBS group, the two questions that included the option "vowels are different in these words" display an immodest proportion of the responses $(26.5 \%$ and $34 \%$ respectively). On the far right-hand side of the graph, we see words such 
as popular and golf, which correspond to common anglicisms in Serbian, popularan and golf, which could explain such a high proportion of o-like answers.

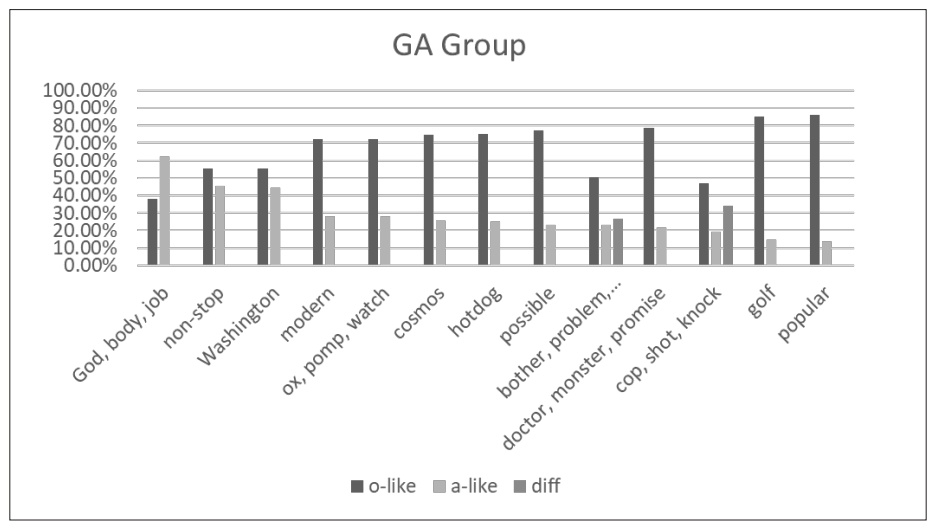

Graph 6: GA group's responses to questions 7-19

Finally, in Graph 7 we single out the results of a subset of GA participants, namely those who consistently picked the GA-appropriate features in questions 4-6; we call these the Consistent GA subgroup. Broadly speaking, these are the students who not only say they use GA more often, but also who are pronunciation-conscious enough to be aware of the main features of GA, based on their responses in questions 4-6. We can see that for each question the consistent GA subgroup, unsurprisingly, had a higher percentage of GA-appropriate answers, with God, body, job exceeding $80 \%$. The descending order of questions is somewhat similar, with a few noticeable exceptions. However, strikingly, even this subgroup of the GA group, in most questions, scores below $50 \%$. 


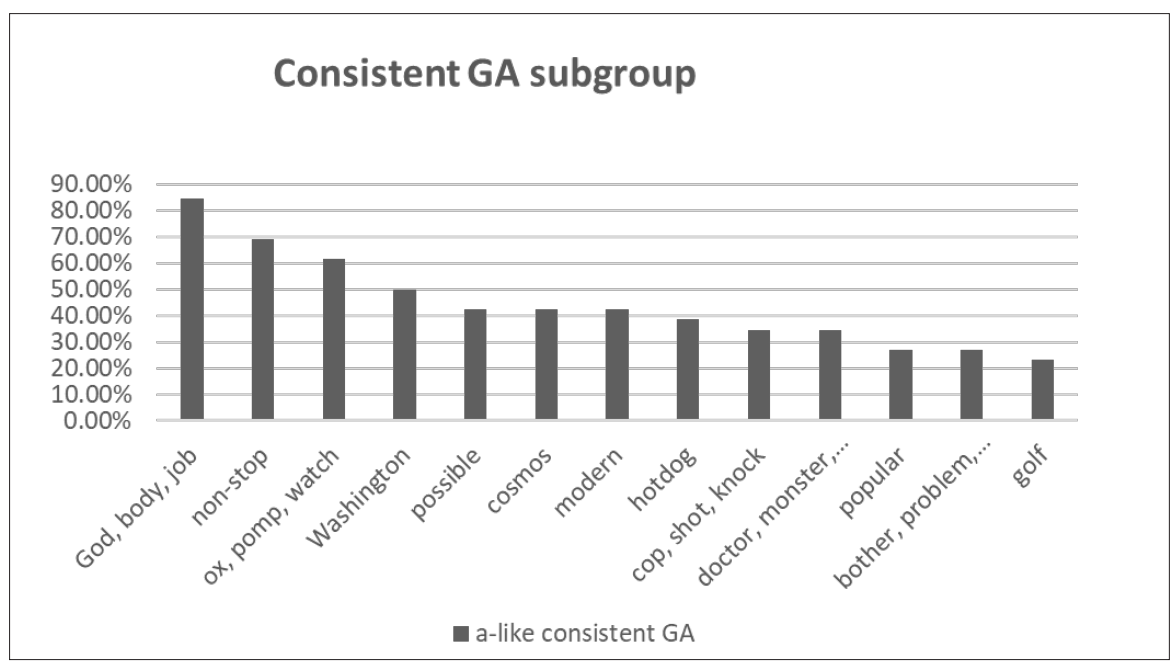

Graph 7: Consistent GA subgroup's responses to questions 7-19

We will now turn to discussing the most striking results pertaining to the pronunciation of the LOT vowel.

God, body, job - our hypothesis was confirmed, inasmuch as these everyday words, commonly heard in the media, lead the majority of GA students to the appropriate response, and thus to the highest proporition of appropriate responses (62\% for the entire GA group, and $85 \%$ for the Consistent GA subgroup).

Cop, shot, knock - on the other hand, with these, presumably equally common words, the participants fared much worse (19\% GA group, 35\% Consistent GA), although this is undoubtedly at least partly due to the fact that they were offered the extra option, namely "vowels are different in these words", which a considerable number of them tended to choose whenever it was offered (25-35\% of the participants). This choice points out that these respondents are uncertain about the pronunciation of some lexical items investigated in the survey.

Ox, pomp, watch - this group of words leads to a big difference between the Consistent GA group and the rest of the GA group. Namely, the former achieved a score of over $60 \%$ in these less common/unusually spelled words, whereas the latter had a score of around $10 \%$.

Non-stop - this anglicism performed quite differently than the rest, which could mean it is much more frequently heard. Specifically, this 
Andrej Bjelaković, Biljana Čubrović: Attitudes Regarding the Realisation...

word had the second-highest scoring, with over $40 \%$ (almost $70 \%$ in the Consistent GA group).

Washington - this word came in third (fourth for the Consistent GA subgroup) in terms of the GA-appropriate response score, possibly suggesting that a number of students are easily influenced by the spelling.

When it comes to other words, such as most anglicisms as well as polysyllabic words (popular, possible, hotdog, golf, bother, problem, common, doctor, monster, promise), the participants performed on the whole more or less consistently, but showed rather low scores (around 20\% for the GA group overall).

\section{Final remarks}

One of the most noticeable findings of the current study is the fact that there is a large discrepancy in terms of choosing appropriate responses between the smaller SBS group and the larger GA group, with the former performing much better - appropriate response rate of $85 \%$ when it comes to the LOT vowel questions, as opposed to $29 \%$ the GA group achieved). This could suggest that the minority of students who opt for SBS, i.e. those who eschew the now default option of picking the variety they are almost certainly more exposed to, tend to be higher-achieving and more pronunciation-conscious.

The degree of uncertainty and vacillation when it comes to the standard lexical set Lот is best illustrated by the fact that a sizeable proportion of participants chose the "vowels are different in these words" option whenever it was offered. The frequently heard, common words did fare somewhat better than average, but only to a degree. Overall, in the aforementioned gradual drift towards American pronunciation, the LOT vowel presents itself as a stumbling block for Serbian advanced learners of English.

Finally, the fact that even the Consistent GA group had trouble choosing the GA-appropriate response a lot of the time clearly reflects the amalgam nature of most students' speech. Some form of the previously mentioned "amalgam of native speaker Englishes, together with some local features arising from a local L1" (Cruttenden 2014: 327) seems to be what most of our participants speak. The results of the present survey thus suggest 
that the label of Amalgam English is on the whole appropriate even for advanced Serbian learners of English.

\section{References}

Bayard, D., C. Gallois, A. Weatherall and J. Pittam (2001). Pax Americana? Accent Attitudinal Evaluations in New Zealand, Australia and America. Journal of Sociolinguistics, 5, 22-49.

Bradac, J. and H. Giles (1991). Social and Educational Consequences of Language Attitudes. Moderna Språk, 85, 1-11.

Bjelaković, A. (2015). "Caught between an RP Rock and a GA Hard Place: Serbian Students' Pronunciation Preferences". Presented at ELLSTAT (English Language and Literature Studies: Tradition and Transformation), October $23^{\text {rd }}$ and $24^{\text {th }}, 2015$ at the Faculty of Philology, University of Belgrade. (25 November 2021) <https:// www.researchgate.net/publication/343391118_Bjelakovic_A_2015 Caught_between_an_RP_rock_and_a_GA_hard_place_Serbian_ students'_pronunciation_preferences $>$.

Bjelaković, A. (2018). Vokali savremenog standardnog britanskog izgovora i njihovo usvajanje kod izvornih govornika srpskog jezika [Contemporary Standard British Vowels and Their Acquisition by Native Speakers of Serbian]. Unpublished doctoral dissertation, University of Belgrade.

Cruttenden, A. (2014). Gimson's Pronunciation of English. $8^{\text {th }}$ edition. London and New York: Routledge.

Čubrović, B. and A. Bjelaković (2020a). Pronunciation Model Selection, or Do You Speak American?. In: B. Čubrović (ed.), BELLS90 Proceedings, Vol. 1. Belgrade: Faculty of Philology, 139-151.

Čubrović, B. and A. Bjelaković (2020b). Standard Southern British as a Pronunciation Model in the Serbian EFL Classroom. In: P. Penda, Ž. Babić and T. Bijelić (eds.), Beyond Hermeneutics: Challenging Traditional Approaches to Literary and Linguistic Studies. Banja Luka: University of Banja Luka, Faculty of Philology, 99-110.

Dobson, E. J. (1957). English Pronunciation 1500-1700. Oxford: Clarendon Press.

Graddol, D., T. McArtur, D. Flack and J. Amey (1999). English around the World. In: D. Graddol and U. H. Meinhoff (eds.), English in a Changing World. The AILA Review, 13, 3-18. 
Andrej Bjelaković, Biljana Čubrović: Attitudes Regarding the Realisation...

Grama, J. and R. Kennedy (2019). Dimensions of Variance and Contrast in the Low Back Merger and the Low-Back-Merger Shift. The Publication of the American Dialect Society, 104/1, 31-55.

Gussenhoven, C. (1992). A New Pronunciation Dictionary of English, or LPD VS EPD. English Studies, 73, 471-478.

Hommel, M. P. (2017). Speech Perception Training as a Serious Game in the EFL classroom. In: O. Engwall and J. Davis Lopes (eds.), Proceedings of the Seventh ISCA Workshop on Speech and Language Technology in Education, 177-180.

Kalaldeh, R. (2016). English Pronunciation Errors by Jordanian University Students. Arab World English Journal (AWEJ), 7/2, 394-416.

Kautzsch, A. (2012). Transfer, Similarity or Lack of Awareness? Inconsistencies of German Learners in the Pronunciation of LOT, THOUGHT, STRUT, PALM and BATH. Research in Language, 10/2, 225241.

Kautzsch, A. (2017). The Attainment of an English Accent: British and American Features in Advanced German Learners. Frankfurt: Peter Lang.

Krapp, G. P. (1925). The English Language in America. Vol. 2. New York: The Century Co.

Labov, W., S. Ash and C. Boberg (2006). The Atlas of North American English. Berlin: Mouton de Gruyter.

Ladegaard, H. J. (1998). National Stereotypes and Language Attitudes: The Perception of British, American and Australian Language and Culture in Denmark. Language and Communication, 18, 251-274.

Ladegaard, H. J. and I. Sachdev (2006). "I Like the Americans... But I Certainly Don't Aim for an American Accent": Language Attitudes, Vitality and Foreign Language Learning in Denmark. Journal of Multilingual and Multicultural Development, 27(2), 91-108.

Paunović, T. (2009). Plus ça change. Poznań Studies in Contemporary Linguistics, 45(4), 525-547. doi:10.2478/v10010-009-0027-1

Rindal, U. (2010). Constructing Identity with L2: Pronunciation and Attitudes among Norwegian Learners of English. Journal of Sociolinguistics, 14/2, 340-261.

Rindal, U. and C. Piercy (2013). Being 'Neutral'? English Pronunciation among Norwegian Learners. World Englishes, 32/2, 211-229.

Van der Haagen, E. (1998). Caught between Norms: The English Pronunciation of Dutch Learners. The Hague: Holland Academic Graphics. 
Wells, J. C. (1982). Accents of English. Cambridge: Cambridge University Press.

Received: 29 September 2021

Accepted for publication: 15 October 2021 